\title{
Üçgen Alan Değişimi Yönteminin Deprem Ön Kestiriminde Kullanılabilirliği: 23.10.2011-13:41 Mw=7.2 Van Depremi Örneği
}

\author{
Usability of Triangular Area Change Method in Earthquake \\ Prediction: 23.10.2011-13: $41 \mathrm{Mw}=$ 7.2 Van Earthquake \\ Example
}

\author{
Ahmet Yücel Ürüşan ${ }^{1 *}$ \\ 1 İstanbul Gelişim Üniversitesi, Mühendislik ve Mimarlık Fakültesi, İnşaat Mühendisliği Bölümü, İstanbul, TÜRKiYE \\ Sorumlu Yazar / Corresponding Author*: ayurusan@gelisim.edu.tr \\ Geliş Tarihi / Received: 19.10.2019 Araştırma Makalesi/Research Article \\ Kabul Tarihi / Accepted: 13.05.2020 DOI:10.21205/deufmd.2020226616 \\ Atıfsekli/How to cite: URUSAN, A.Y.,(2020). Üçgen Alan Değişimi Yönteminin Deprem Ön Kestiriminde Kullanılabilirliği: 23.10.2011-13:41 \\ $M w=7.2$ Van Depremi Örneği. DEUFMD 22(66), 813-824.
}

Öz

Plaka tektoniği nedeniyle meydana gelen depremler beklenmeyen olaylardır. Depremler, öncesinde hareket, eğilme, gerilme, elektromanyetik dalga emisyonu gibi stres nedeniyle yerüstü veya yeraltında meydana gelen bazı öncü ișaretler verirler. Bunlar çeșitli metotlarla algılanırlar. Fakat bu işaretler her zaman depremlerle ilişkilendirilemez. Bu nedenle bilim adamları daha fazla nicelik araștırarak deprem tahminini iyileștirmeye çalıșmaktadırlar. Özellikle son yıllarda bu konuda anlamlı sonuçlar elde edilmiştir. Üzerinde fazla tartışılmamasına rağmen en iyi metotlardan biri, eğer deprem dışmerkezi etrafında sabit GPS referans istasyonları varsa, bu istasyonlar arasında oluşturulacak üçgenlerin alanlarında bir değişim olup olmadığının araștırılmasıdır. Yöntem, bu araştırmada, 23 Ekim 2011 - 13:41'de 7.2 M büyüklüğünde meydana gelen Van depremi öncesi ve deprem anındaki zemin hareketlerini incelemede kullanılmıștır. Bu amaçla, sürekli gözlem yapabilen sabit GPS referans istasyonları ağı (TUSAGA-Aktif, Continuously Operating Reference Station-CORSTR) verisinden yararlanılmıştır. Van depreminin oluştuğu fay düzleminin her iki yanında yer alan yakın plandaki 14 istasyon verisi ele alınmıș ve günlük hareket vektörleri incelenmiștir. İstasyonlar arası uzaklıkların değişimi ile bunların oluşturduğu üçgen alanlarındaki günlük değişim oranları hesaplanmıştır. Elde edilen sonuçlar deprem öncesi yer değiștirmede anomalilerin yakalandığı, bunların depremin öncü ișaretleri olabileceği, ancak esas yer değiștirmenin deprem esnasında olduğunu göstermektedir. Ardından, bu çözümler deprem öncesi sismik veri ile karşılaştırılmıştır. Sismik verisine göre deprem öncesinde büyüklüğü $2 \leq M \leq 4$ arasında olan birçok minör depremin meydana geldiği, bu depremlerin CORS verisinden elde edilen üçgenlerin günlük alan değişim oranlarıyla uyumlu olduğu görülmüștür.

Anahtar Kelimeler: Deprem tahmini, Üçgen alanlar, Plaka Tektoniği, Mikro sismik hareketler, GPS

\section{Abstract}

Earthquakes caused by plate tectonics are unexpected events. Earthquakes give some precursor signals that occur above ground or underground due to stress such as movement, bending, stress, electromagnetic wave emission. They are detected by various methods. But these signs can not be always associated with earthquakes. Therefore, scientists are trying to improve the earthquake 
prediction by searching for more quantity. Significant results have been obtained especially in recent years. Although not discussed much, one of the best methods is to investigate if there is a changing in the area of triangles to be created between these stations if there are fixed GPS reference stations around the earthquake epicenter. In this research, this method has been used to investigate the ground movements before and during the Van earthquake which occured 7.2 M magnitude at 13:41 on 23rd October 2011. For this purpose, the data of Continuously Operating Reference Station (CORSTR) was used. The data of 14 stations in the near plan located on both sides of the fault plane where the Van earthquake occurred has been taken into consideration and daily motion vectors have been examined. The variation of the distances between the stations and the daily change rates in the triangular areas formed by them have been calculated. The results show that pre-earthquake displacement anomalies heve been detected and these may be the precursor signs of the earthquake, but it has also seen that the biggest displacement was during the earthquake. Then, these solutions have been compared with the seismic data that belong before the earthquake. According to the seismic data, many minor earthquakes with magnitudes between $2 \leq \mathrm{M} \leq 4$ occurred before the earthquake, and this case is absolutely coherent with the daily area change rates of the triangles which have been obtained from CORS data.

Keywords: Earthquake prediction, Triangular fields, Plate tectonic, Micro seismic motions, GPS

\section{Giriş}

Antik çağlardan beri insanoğlu deprem gibi doğa olaylarından her zaman etkilenmiștir. Ancak her zaman depremin zararının en aza indirilmesi için çaba harcamıștır. Diğer taraftan, pek çok parametrik olguya sahip depremin ne zaman ve nerede olacağı konusunda kesin bir tahmin yürütmek de çok zordur. Teknolojinin, bilimin ve yeni, etkili araştırma olanaklarının gelişmesi ile birlikte, incelenebilen ve takip edilebilen parametre sayısı artmış ve bu çalışmalardan günden güne daha anlamlı sonuçlar elde edilmeye başlanmıştır.

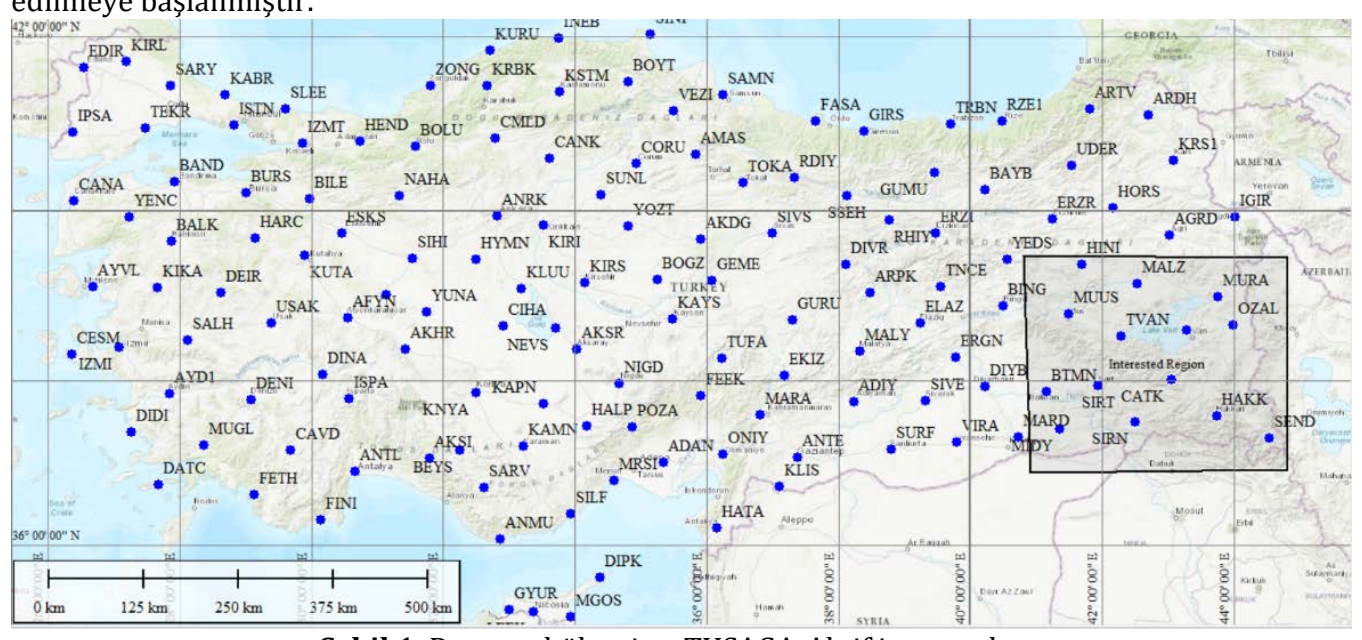

Şekil 1. Deprem bölgesi ve TUSAGA-Aktif istasyonları.

Deprem tahminine yönelik yapılan bazı TEC değeri çalışmalarında, örneğin; 2011 Thoko-Oki ( $\left.\mathrm{M}_{\mathrm{w}} 9.0\right), 2010$ Chile $\left(\mathrm{M}_{\mathrm{w}} 8.8\right), 2004$ Sumatra-
Deprem tahmininde göz önüne alınan bazı yaygın yöntemler; yeraltı suyu sıcaklığındaki değişimler, deniz suyu seviyesi, mikro sismik hareketler, yer manyetik alanındaki değişimler, Troposferdeki sıcaklık, basınç, nem anomalileri, iyonosferdeki toplam elektron yoğunluğu değişimi (Total Electron Content-TEC), radyo dalgaları üzerindeki elektromanyetik bozulmalar, hayvanların alışılmadık davranışları, yer yüzeyinin eğilmesinin takibi, faylardan çıkan radon gazı artışı, vb. gibi sıralanabilir.

Andaman (Mw9.2) ve 1994 Hokkaido-Toho-Oki $\left(M_{w} 8.3\right)$ depremleri $M 9$ büyüklüğünde olup, büyüklüklerine göre, meydana gelecekleri 
konusunda en az bir saat önceden tahmin edilebilecekleri görülmüştür. [1][2].

İyonosferdeki TEC değișimi yoluyla, Van depremi için 2014 yılında yapılan deprem tahmin çalışmasında depremden 50 dakika önce TEC değerlerinde nasıl bir düşüş yaşandığl, bunun ilk işaretlerinin günler öncesinden GPS verisine ne șekilde yansıdığı ortaya konulmuștur [3]. Bu araștırmada deprem bölgesindeki 14 TUSAGA-Aktif (CORS-TR) istasyonu göz önüne alınmış ve günlük plaka hareketleri incelenmiștir. Böylece deprem sırasında oluşan fayın ne tip bir fay olduğu, depremin mekanizması ve CORS istasyonlarının deprem öncesi ve deprem anında kaç $\mathrm{mm}$ ve hangi yönde deplasmana uğradıkları (bu yön ve deplasman "hız vektörleri" şeklinde ifade edilmektedir) konusunda sonuçlara varılmıștır [3]. Sekil 1'de, Türkiye'nin doğusunda yer alan gölgelendirilmiş bölge, 23 Ekim 2011'de meydana gelen Van deprem bölgesini ve mavi noktalar ise Türkiye genelinde ve bölgede 2009 yllında kurulmuş olan, sürekli gözlem yapan sabit GPS referans istasyonlarını TUSAGA-Aktif göstermektedir. Şekil 2'de ise deprem bölgesi ve bölgede deprem gününü de içine alan 4 aylık bir zaman dilimi içinde meydana gelen depremler gösterilmektedir. Boğaziçi Üniversitesi, Kandilli Rasathanesi'nden edinilen aylık raporlarda bölgeye özel olarak filtrelenen sismik veriye göre beyaz noktalar $2 \leq \mathrm{M} \leq 4$, Sarl noktalar $4 \leq \mathrm{M} \leq 4.9$, turuncu noktalar $5 \leq \mathrm{M} \leq 6$ ve Kırmızı yıldız işareti ise $7.2 \mathrm{M}$ büyüklüğünde depremleri işaret etmektedir. Burada $5 \leq \mathrm{M} \leq 6$ depremlerin tamamı ana şoktan sonra meydana gelmiştir.

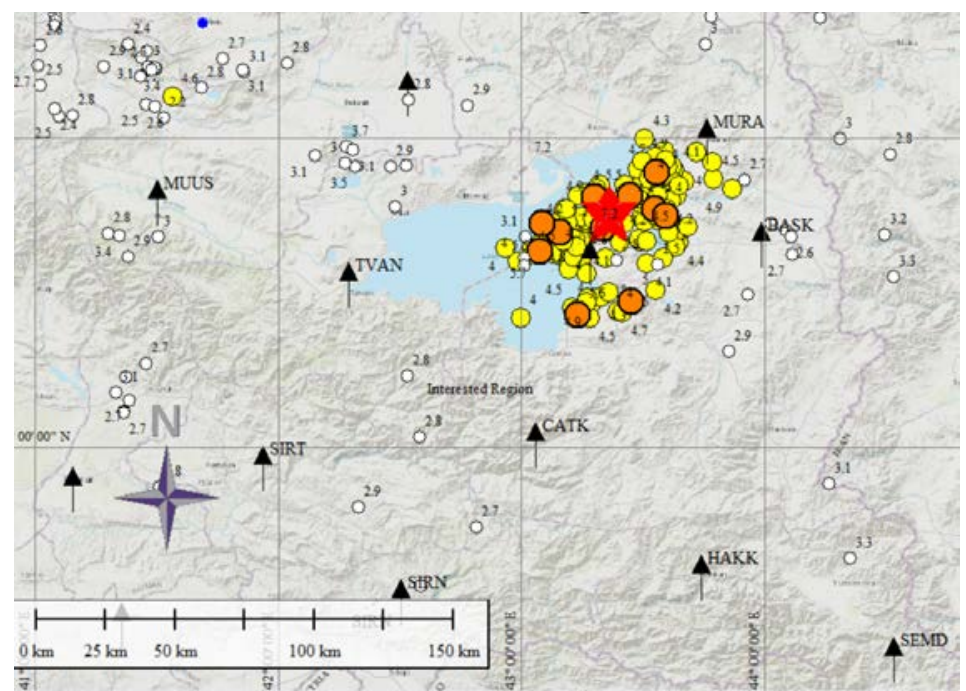

Şekil 2. Deprem bölgesi. Boğaziçi Üniversitesi, Kandilli Rasathanesinden alınan ve deprem gününü de içeren 4 aylık sismik veri șekilde gösterilmiştir. Burada, beyaz noktalar $2 \leq \mathrm{M} \leq 4$, Sarı noktalar $4 \leq \mathrm{M} \leq 4.9$, turuncu noktalar $5 \leq \mathrm{M} \leq 6$ ve Kırmızı yıldız işareti ise $7.2 \mathrm{M}$ büyüklügünde depremleri işaret etmektedir.

GAMIT/GLOBK [4] programı kullanılarak 118 günlük (dört aylı) veri (Jülyen gününe göre 235-353) ișlenmiş ve zaman serileri elde edilmiştir. Van depremi Jülyen günü olarak 296. günde meydana gelmiștir ve incelenen günler dahilindedir.

Araștırmadan elde edilen bulgulara göre bölgede, deprem diș merkezinin kuzeyinde kalan MURA (Muradiye) ve güneyindeki BASK(Başkale) ve HAKK (Hakkâri) gibi bazı istasyonlar birbirlerine yaklaşmıștır. Elde edilen bu sonuç ile bölgede bir ters faylanma olup olmadığı araştırılmıtır. Literatür taraması ve raporlar incelendiğinde ters faylanmanın deprem dıș merkezinin güneyinde, Van ve Erçek gölleri arasında daha önce varlığı bilinmeyen ve Şekil 3'de kırmızı ile gösterildiği şekilde meydana geldiği anlaşılmıştır [1] [3]. 


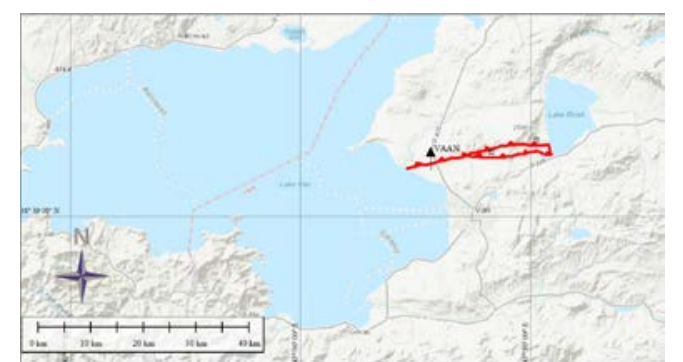

Şekil 3. Van depreminin bir sonucu olarak oluşan daha önce varlığı bilinmeyen fay (hayalet

fay) kırmızı ile gösterilen ters faylanma meydana geldiği anlaşılmıştır. Yapılan literatür taramasında bu durumun arazi incelemeleriyle

de uyumlu olduğu görülmüștür [1] [3].

\section{Materyal ve Metot}

\section{1. Üçgen alanlar yöntemi}

Başta topoğrafik haritalar ve eğri yüzeyler olmak üzere pek çok alanda kullanılan üçgenlere bölme yöntemi deprem tahmini konusunda ilk kez Tokachi, Nigata, West Fukuoka, KwasakiFujisawa-Ninomiya ve Sumatra depremleri için kullanılmıștır [2][5]. Calıșma, deprem öncesi mekanizma bilinmediğinden ötürü, 3 boyutta $\mathrm{X}$, Y, Z'nin bütün kombinasyonları için Japonya'da bulunan GPS sabit referans istasyonlarının verileri kullanılarak yapılmıștır. Burada istasyonlar arasında oluşturulan üçgen alanlarının günlük değişim oranları araştırılmış ve bunun için (1) formülü kullanılmıştır. Birimi ppm dir[2].

$$
D C R=\frac{A C D-A P D}{A P D}
$$

Burada;

DCR: Daily Change Ratio - Günlük değişim oranı

ACD: Area of Current Day - İçinde bulunulan gün için üçgen alanı

APD: Area of Previous Day - Önceki gün hesaplanan üçgen alanı.

Deprem tahmini açısından sonuçlar çok anlamlı olarak değerlendirilebilir. Hangi üçgen alanlarının değiștiği, potansiyel deprem tehlikesinin nerede olduğu konusunda da bir fikir verebilir [2].

Tokachi depremi için merkez üssü etrafındaki CORS istasyonlarının köșe noktalarını oluşturduğu üçgenleri meydana getirilmiştir ve bunların alanlarındaki günlük değișim oranları hesaplanmıștır. Sonuçlara bakıldığında 26 Eylül'de meydana gelen $8.0 \mathrm{M}$ büyüklüğündeki depremden günler önce, tam 11 gün, ilk öncü ișareti alınmıștır.Yine bu araștırma gurubu tarafından Nigata, West Fukuoka, KwasakiFujisawa-Ninomiya ve Sumatra depremleri için yapılan diğer çalışma sonuçlarına bakıldı ̆̆ında, herhangi bir depremin ilk sinyallerinin, seçilen sismik bilgi temelinde, depremden minimum üç gün önce GPS istasyon verisinden ortaya çıkarılabildiği görülmüştür [2][5].

Benzer bir çalışmada, Van depremi için üçgen alanlar yöntemi kullanılmış ve anlamlı sonuçlar elde edilmiştir [6].

\subsection{GAMIT/GLOBK yazılımı ile verilerin değerlendirilmesi}

GAMIT programı, GLOBK ve Track programları ile birlikte bir paket olarak MIT, Scripps Oşinografi Enstitüsü ve Harvard Üniversitesi tarafından Ulusal Bilim Vakfı desteğiyle ABD'de geliştirilmiş bir programdır. Bu program kabuk deformasyonunu incelemek maksadıyla GNSS verilerini işlemek için kullanılır. Program, yer istasyonlarının ve uydu yörüngelerinin, atmosferik zenit gecikmelerinin ve yer oryantasyon parametrelerinin üç boyutlu göreceli konumlarını tahmin etmek için faz verilerini işleyecek kodlardan oluşmuştur ve UNIX işletim sisteminde çalışacak șekilde tasarlanmıştır.

Uydudan sabit yer istasyonuna gelen GNSS sinyalleri çeşitli baskın hatalar nedeniyle istenilen doğrulukta olamamaktadır. $\mathrm{Bu}$ hataların kaynakları; uydu-yer istasyonu arasındaki iyonosfer ve troposfer tabakalarında meydana gelen gecikme, uydu ve yer istasyonu arasındaki saat farkı, gibi sıralanabilir. Bunları giderebilmek için geliştirilen modelleri (iyonosfer için tek tabaka modelini, troposfer için Saastamonien modeli ve küresel haritalama fonksiyonları, vb) içeren program, yer istasyonu ve uydu arasındaki bu hata kaynaklarından dolayı meydana gelen ve metreler mertebesine varan faz kaymalarını, uluslararası sabit GPS istasyonlarını da referans alarak çözer. Böylece günlük bazda ilgili istasyonun koordinatlarını en hassas şekilde çözümlemeye çalışır.

GAMIT/GLOBK ile günlük çözülen bu koordinat değişimleri Şekil 4'de bir örneği görülen [3] zaman serisine dönüștürülür ve bu günlük koordinatlar o istasyona ait haftalık, aylık, yıllık hareket vektörleri haline getirilir. 
Track programında ise istasyondan gerçek zamanlı olarak alınan veri kullanılır ve hızlı uydu yörünge verisiyle birleştirilerek istasyon koordinatındaki anlık değişimler izlenebilir ve sebepleri araştırılabilinir.

$\mathrm{Bu}$ çalışmada, toplanan verinin sonradan işlenmesi anlamına gelen, post process de denilen (gerçek zamanlı olmayan), veri değerlendirme yöntemi uygulanmıștır. Depremin meydana geldiği 2011 yllında ITRF2005 datumunda veri sağlayan deprem merkez üssünü çevreleyen 14 TUSAGA-Aktif istasyonu ve Türkiye ve çevresindeki 19 IGS referans istasyonu (ANKR, GLSV, GRAS, GRAZ, ISTA, KIT3, KOSG, MATE, NICO, NOT1, ONSA, POTS, RAMO, SOFI, TUBI, VILL, WTZR, ZECK, ZWEZ) günlük verileri GAMIT/GLOBK programında işlenmiş ve Şekil 5'de de istasyonlara ait hız-zaman çizelgeleri elde edilmiștir.

\section{Bulgular ve Tartışma}

Giriş bölümünde, 2014 yılında yapılan ve Van depremi öncesinde ionosferdeki anormallikleri araştırmaya ilișkin açlklanan sonuçlar ve bu sonuçların bölgede büyük deprem öncesi meydana gelen mikro depremlerle uyumu ortaya konmuş ve özetle Tablo 1 ve Şekil 4'de MURA istasyonu için gösterilmiștir. Sismik veri ile bu istasyona ait deplasman verisi Șekil 4 ve Şekil 5'de görüldügü üzere sırasıyla 237 241, $254,266,271,275,286,292,293,295$ ve deprem günü olan 296 günlerinde uyumludur [3]. Şekil 5 'deki zaman serilerinde özellikle MURA istasyonunun Doğu-Batı ve Kuzey-Güney doğrultularında deplasmanının anlamlı olduğu görülmüștür. Burada, yatay eksenler yılın günlerini ve düșey eksenler milimetrik olarak istasyon hareketini göstermektedir. Serilere göre MURA istasyonu (a) deprem öncesi hareketler gösterse de en büyük taşınmayı deprem günü yapmıș ve 30.6 mm güneye doğru hareket etmiștir. HAKK istasyonuna ait zaman serinde ise (b) özellikle deprem günü $10.5 \mathrm{~mm}$ kuzey yönünde hareket etmiștir. Her iki istasyonun da doğu batı yönünde hemen hemen elastik bir hareket yaptığı görülmekte. MURA istasyonunun yüksekliğinin azaldığı bununda ters faylanmayı ifade eden Şekil 3 ile uyumlu olduğu gözlenmiştir. Şekil 5'de MURA ve HAKK istasyonları için elde edilen zaman serileri diğer 11 istasyon için de elde edilmiștir. Bu zaman serileri Şekil 6'da görülen hareket vektörlerine dönüștürülerek harita üzerinde görselleştirilmiştir.

Bütün bu sonuçlar üçgen alanlarının nasıl değiştiği sorusunu akla getirmiştir. $\mathrm{Bu}$ araștırmanın amacı, özellikle yatay düzlemde bu sorunun cevabını bulmak ve elde edilen çözümleri bu bölgeden alınan mikro sismik veriyle karşılaştırmaktır. $\mathrm{Bu}$ anlamda araştırmada elde edilen bazı değerler aşağıda öncelikli olarak gözden geçirilmiştir.

Bu çalışmada, 2014 yılında yapılan çalışmada olduğu gibi 14 TUSAGA-Aktif istasyonuna ait Tapu Kadastro Genel Müdürlügü̈nün araștırma için kullanıma açtığı dört aylık veri göz önüne alınmıştır[3]. Öncelikle istasyonların hizmete başladığı ilk pozisyonuna göre günlük düzeltme değerleri ve ardından her bir istasyon çifti arasındaki günlük uzaklıklar hesaplanmıș ve Șekil 7'deki grafik elde edilmiștir. Çalıșmada yükseklik değerlerindeki değişimler göz önüne alınmamış, sadece yatayda, enlem ve boylamlar üzerinden hesaplar gerçekleștirilmiștir.

Tablo 1. 23 Ekim 2011 Van depreminden önce meydana gelen depremler ve büyüklükleri [3].

\begin{tabular}{lllllll}
\hline $\begin{array}{l}\text { Nu Jülyen } \\
\text { Günü }\end{array}$ & Tarih & Açıklama & Enlem & Boylam & Mw \\
\hline 1 & 296 & 23.10 .2011 & TABANLI-- (VAN) & 38.7578 & 43.3602 & 7.2 \\
2 & 295 & 22.10 .2011 & GOZTEPE-BULANIK (MUŞ) & 38.9735 & 42.2817 & 3.7 \\
3 & 291 & 18.10 .2011 & BALVEREN-- (ŞIRNAK) & 37.5475 & 42.5875 & 3 \\
4 & 286 & 13.10 .2011 & KIRIKKAYA-AHLAT (BİTLIS) & 38.9095 & 42.317 & 3.5 \\
5 & 282 & 09.10 .2011 & GUNYURDU-BULANIK (MUŞ) & 38.9173 & 42.2778 & 3 \\
6 & 275 & 02.10 .2011 & ATADAMI-DIYADIN (AĞRI) & 39.2992 & 43.7583 & 3 \\
7 & 272 & 29.09 .2011 & YEMISȘEN-BULANIK (MUŞ) & 38.9443 & 42.1523 & 3.1 \\
8 & 271 & 28.09 .2011 & VAN GÖLÜ & 38.682 & 43.018 & 3.1 \\
9 & 266 & 23.09 .2011 & YARLISU-VARTO (MUŞ) & 39.2578 & 41.4395 & 3.1 \\
10 & 265 & 22.09 .2011 & ÇOBANDAĞIVARTO (MUŞ) & 39.2283 & 41.4668 & 3.1
\end{tabular}


DEÜ FMD 22(66), 813-824, 2020

\begin{tabular}{lllllll}
11 & 265 & 22.09 .2011 & ÇOBANDAĞI-VARTO (MUŞ) & 39.2282 & 41.4673 & 3 \\
12 & 264 & 21.09 .2011 & MUŞ & 38.6825 & 41.5063 & 3 \\
13 & 262 & 19.09 .2011 & BEKIRHAN-KOZLUK (BATMAN) & 38.1167 & 41.3643 & 3 \\
14 & 257 & 14.09 .2011 & ÇUKURTARLA-AHLAT (BİTLIS) & 38.913 & 42.5293 & 3 \\
15 & 254 & 11.09 .2011 & ALANIÇİ (MUŞ) & 38.6873 & 41.347 & 3.4 \\
16 & 246 & 03.09 .2011 & TOPÇUDEĞİMENI-GÜRPINAR (VAN) & 37.91 & 43.64 & 3.1 \\
17 & 245 & 02.09 .2011 & YAMANYURT-SARAY (VAN)TÜRKIYE-İRAN SINIR BÖLGESİ & 38.5347 & 44.3215 & 3.3 \\
18 & 241 & 29.08 .2011 & TÜRKIYE-İRAN SINIR BÖLGESI & 38.624 & 44.5253 & 3.2 \\
19 & 240 & 28.08 .2011 & TÜRKIYE-IRAN SINIR BÖLGESI & 38.9963 & 44.4467 & 3 \\
20 & 240 & 28.08 .2011 & TÜRKIYE-IRAN SINIR BÖLGESI & 37.8802 & 44.2228 & 3.1 \\
21 & 238 & 26.08 .2011 & AHLAT (BİTLISS) & 38.7785 & 42.4817 & 3 \\
\hline
\end{tabular}

Şekil 3'te ortaya çıkan hayalet fayın her iki yanındaki 7 istasyon, bunlar MURA, MUUS, VAN, SIRT, HAKK, SIRN, SEMD istasyonlarıdır, köşe noktalarını oluşturmak üzere Şekil 6'de görülen üçgenler oluşturulmuştur.

Şekil 6'da fayın kuzeyindeki bazı CORS istasyonlarının güneye ve güneydeki bazı istasyonlarında kuzeye doğru hareket ettiklerini göstermektedir. Burada özellikle MURA istasyonu güneye doğru $33 \mathrm{~mm}$ ve HAKK kuzeye doğru $10.5 \mathrm{~mm}$ hareketlendikleri görülmektedir. Yine BASK istasyonunun Kuzey-batı yönünde 15 mm'lik bir hareketi söz konusundur.

İstasyonlar arasındaki uzaklıkların hesaplanan günlük değerleri ve bu değerlerin bir önceki güne göre değişimleri metre cinsinden sirasıyla Tablo 2, ve Tablo 3'te gösterilmiștir. Şekil 7'de ise, Tablo 3'te verilen bu günlük değişimlerin nasıl bir esneklik gösterdikleri açıkça görülmektedir. Ancak depremin meydana geldiği 296. gün öncesinde bazı günler var ki, 286, 287, 290, 293 gibi, bu günlerde değișim değerlerinin oransal olarak daha büyük olduğu așikardır. Bu durum, ilk bölümde anlatılan ve Şekil 2'de gösterilen deprem gününü de içeren 4 aylık Kandilli Rasathanesi raporlarından bu bölge için elde edilen sismik veri ile de örtüşmektedir. Uzaklık değişim oranları, MURAMUUS, MURA-HAKK, MURA-SIRT, MURA-TVAN, HAKK-SIRN, SIRN-SIRT çiftleri için 286, 287, 290, 293 Jülyen günlerinde benzer yönde değişim göstermektedirler. Bazı diğer istasyon çiftleri için ise (MUUS-SIRT, MUUS-TVAN, HAKKSEMD, SIRT-TVAN) bu değișimler 1. gruba göre aksi şekildedir. Bu gruptaki istasyonların uzaklık değerleri günlük değişim oranları olarak 1 . Gruba göre, 293 ve 294 günleri dıșında, zıt yönde, yani, bazı günler için büyürken bazı günler için ise küçülmektedir. 293. ve 294. günlerde bütün uzaklık oranları, sırasıyla, maksimum $0.005 \mathrm{~m} \mathrm{(+)} \mathrm{veya} 0.005 \mathrm{~m} \mathrm{(-)}$ yönde değişmektedir. İstasyonlar arası deplasman değerlerinin toplamda, sirasıyla, $0,012 \mathrm{~m}$ ve 0,01 m şeklinde değiştiği 286-287 ve 289-290 günleri, yaklaşmakta olan depremin ilk sinyalleri ve dolayısıyla deprem tahmini açısından çok önemlidir. Bu öncü işaretler ve meydana gelen birçok düşük aletsel büyüklüğe sahip depremler yeraltında büyük bir stresin oluştuğunun ve yakın gelecekte büyük bir depremin olacağının işaretçisidir. Sonuç olarak Şekil 7, 296. günde meydana gelen büyük depremde (7.2M) istasyon çiftleri arasındaki uzaklığın da nasıl değiştiğini ortaya koymaktadır. Buna göre; kuzey-güney doğrultusunda istasyonlar arası uzaklıkların 0,045 m'ye kadar kısalma (- yönde olduğundan bu anlaşılmaktadır) değişiklik gösterdiğini göstermektedir. Başka bir değişle, istasyonlar birbirine yaklaşmışlardır. Bu da bize bölgede bir ters faylanma olduğunu net olarak ispat eder ki bu sonuç Şekil 3'deki sonuçla örtüşmektedir. Burada başka bir sonuç olarak da faylanmanın doğu-batı yönünde ve istasyonlar arası mesafenin azaldığı, dış merkeze göre kuzeyde MURA ve güneyde BASK, HAKK, SIRN, SIRT, SEMD arasında, özellikle, zaman serisi ve hız vektöründen de anlaşlacağı gibi MURA istasyonuna yakın bir bölgede olduğu anlaşılmaktadır. Elde edilen hız vektörleri ayrıca Anadolu plakasında meydana bu sıkışma sonucunda özellikle MUUS istasyonunun batıya doğru bir deplasmana sahip olduğunu göstermektedir. Bu da Anadolu plakasının çok bilinen batı yönündeki hareketi ile uyumlu bir çıktıdır 
DEÜ FMD 22(66), 813-824, 2020

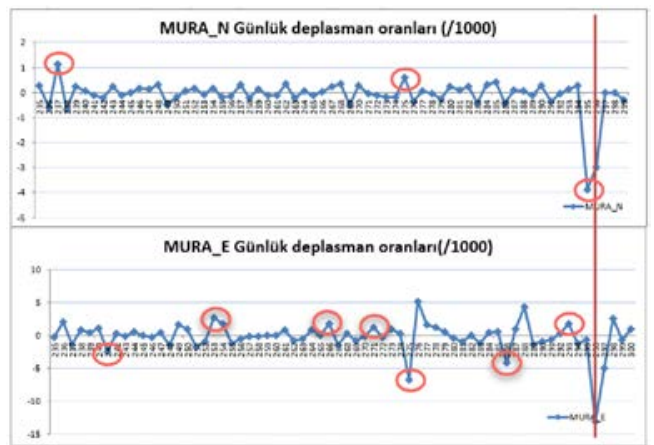

ilișkisi. Bu istasyona ait Şekil 5'te zaman serilerinde görülen deplasman verisi, kırmızı dairelerle gösterilen sirasiyla 237 241, 254, 266, 271, 275, 286, 292, 293, 295 ve deprem günü olan 296 günlerindeki sismik veriyle (Tablo 1) uyumludur. [3]

Şekil 4. MURA istasyonu için GPS ve sismik veri

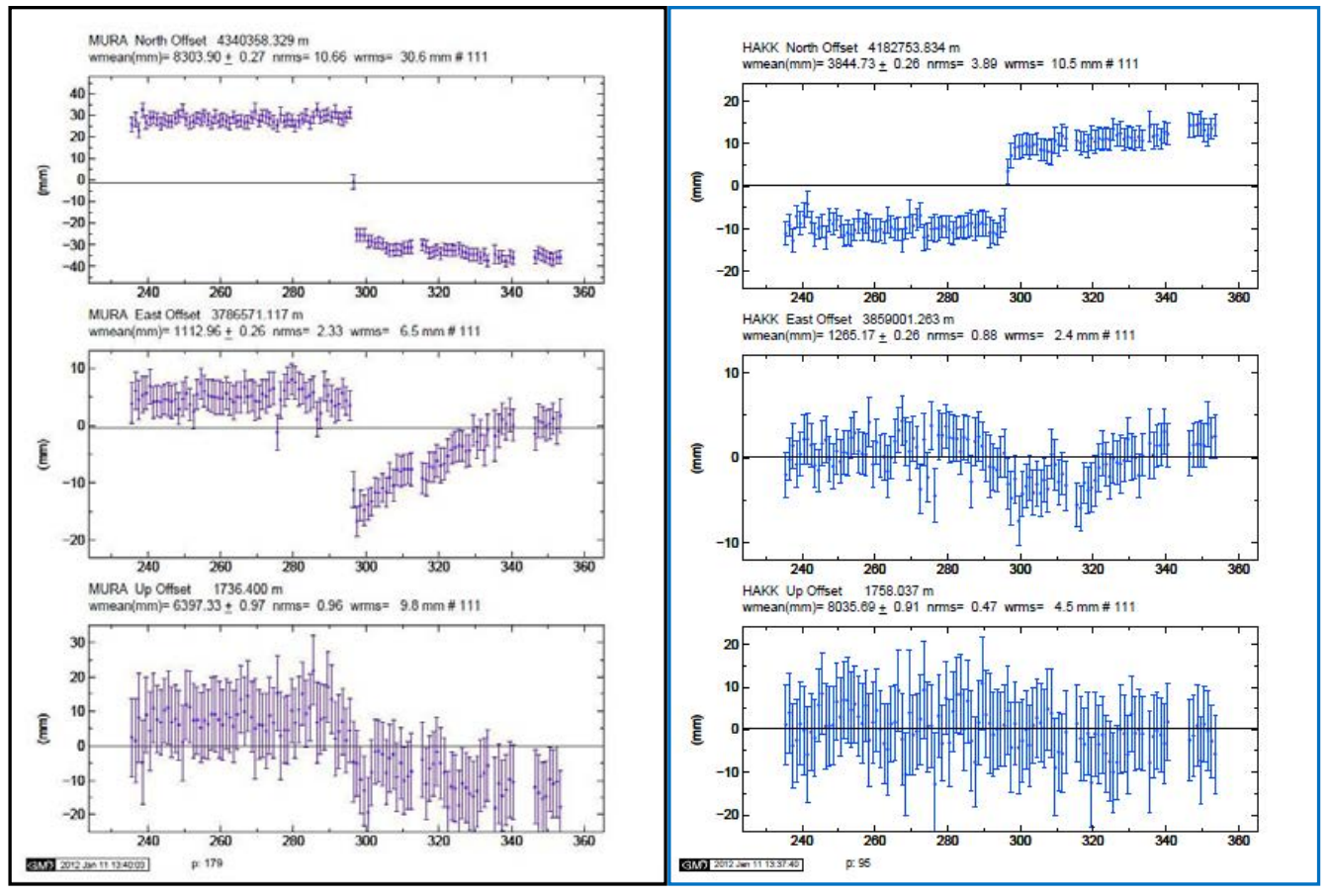

Şekil 5. GNSS verisi kullanılarak GAMIT/GLOBK programından MURA ve HAKK istasyonları için elde edilen (a) Kuzey-Güney, (b) Doğu-Batı ve (c) Yükseklik zaman serileri [3]. 
DEÜ FMD 22(66), 813-824, 2020

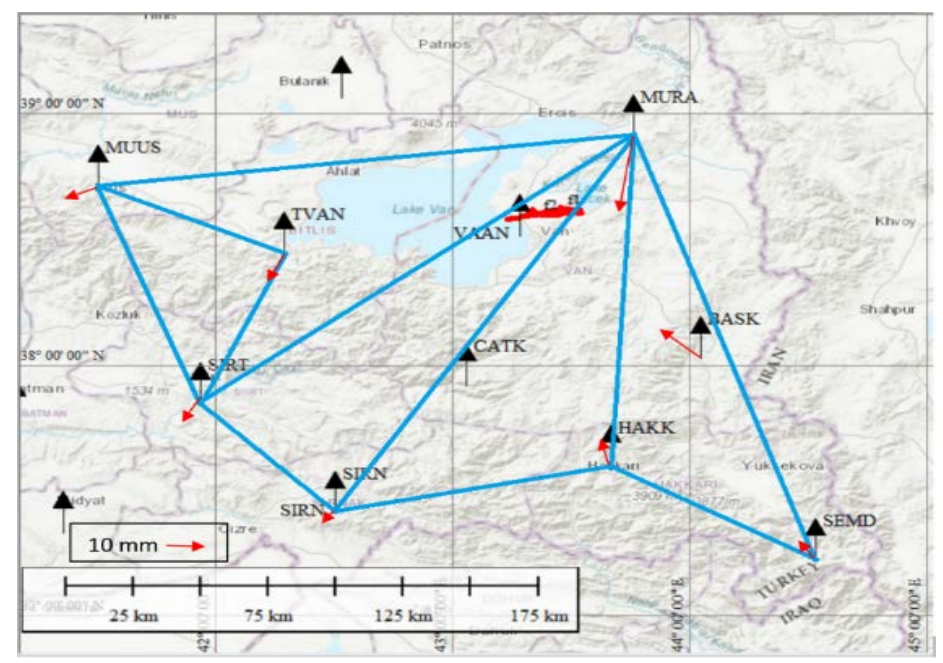

Şekil 6. 7 referans istasyonunun köşe noktası olarak kullanılmasıyla elde edilen 5 üçgen.

Tablo 2. CORS istasyonları arasındaki uzaklıklar (m)

OLUŞTURULAN İSTASYON ÇIFTLERI ARASINDAKI UZAKLIK DEĞERLERI - L (m)

\begin{tabular}{|c|c|c|c|c|c|c|c|c|c|c|}
\hline $\begin{array}{l}\text { MURA- } \\
\text { HAKK }\end{array}$ & $\begin{array}{l}\text { MURA- } \\
\text { SIRN }\end{array}$ & $\begin{array}{l}\text { HAKK- } \\
\text { SIRN }\end{array}$ & $\begin{array}{l}\text { MURA- } \\
\text { SIRT }\end{array}$ & $\begin{array}{l}\text { SIRN- } \\
\text { SIRT }\end{array}$ & $\begin{array}{l}\text { MURA- } \\
\text { MUUS }\end{array}$ & $\begin{array}{l}\text { MUUS- } \\
\text { SIRT }\end{array}$ & $\begin{array}{l}\text { SIRT- } \\
\text { TVAN }\end{array}$ & $\begin{array}{l}\text { MUUS- } \\
\text { TVAN }\end{array}$ & $\begin{array}{l}\text { HAKK- } \\
\text { SEMD }\end{array}$ & $\begin{array}{l}\text { MURA- } \\
\text { SEMD }\end{array}$ \\
\hline 157207.962 & $2 \quad 198829.0793$ & 113470.0845 & $\begin{array}{ll}5 & 198120.6522\end{array}$ & 64443.0371 & 197404.8852 & 102857.717 & 73268.73817 & 74615.57105 & $5 \quad 79704.80291$ & 200115.4944 \\
\hline 157207.9618 & $\begin{array}{ll}8 & 198829.0783\end{array}$ & 3113470.0778 & $\begin{array}{ll}8 & 198120.6499\end{array}$ & 64443.03895 & 197404.8912 & 102857.7176 & 73268.73739 & 74615.57282 & $2 \quad 79704.81308$ & 200115.4978 \\
\hline 157207.9634 & $\begin{array}{ll}4 & 198829.0799\end{array}$ & 113470.0835 & $\begin{array}{ll}5 & 198120.6548\end{array}$ & 64443.04068 & 197404.8868 & 3 102857.7173 & 73268.73736 & $5 \quad 74615.57381$ & $\begin{array}{l}1 \quad 79704.81191\end{array}$ & 200115.4979 \\
\hline 157207.96 & $\begin{array}{ll}6 & 198829.0779\end{array}$ & 7 113470.0851 & $\begin{array}{ll}1 & 198120.6513\end{array}$ & 64443.04145 & 197404.8817 & 102857.715 & 73268.73839 & 74615.56751 & $1 \quad 79704.81042$ & 200115.4967 \\
\hline 157207.9623 & 198829.077 & $7 \quad 113470.0787$ & $7 \quad 198120.6521$ & 64443.03689 & 197404.8885 & 102857.7077 & 73268.7321 & 74615.571 & 79704.81274 & 200115.4946 \\
\hline 157207.9648 & $8 \quad 198829.0795$ & $5 \quad 113470.0849$ & $9 \quad 198120.6556$ & 64443.0431 & 197404.8943 & 102857.7097 & 73268.73715 & 74615.57041 & $1 \quad 79704.80627$ & 200115.5018 \\
\hline 157207.9622 & $2 \quad 198829.0772$ & 113470.0773 & $\begin{array}{l}3 \quad 198120.6526\end{array}$ & 64443.04236 & 197404.8821 & 102857.7174 & 73268.7383 & 74615.57385 & $5 \quad 79704.81282$ & 200115.4969 \\
\hline 157207.9621 & $\begin{array}{ll}1 & 198829.0793\end{array}$ & 113470.0796 & $\begin{array}{ll}6 & 198120.6546\end{array}$ & 64443.043 & 197404.8847 & 102857.7156 & 73268.73813 & 74615.56962 & 79704.80462 & 200115.495 \\
\hline 157207.9627 & $\begin{array}{ll}7 & 198829.0825\end{array}$ & $5 \quad 113470.082$ & $2 \quad 198120.6603$ & 64443.04159 & 197404.8825 & 102857.7204 & 73268.7379 & 74615.56943 & $\begin{array}{ll}3 & 79704.81505\end{array}$ & 200115.5008 \\
\hline 157207.9621 & $\begin{array}{ll}1 & 198829.0796\end{array}$ & 5 113470.0828 & $8 \quad 198120.6516$ & 64443.04274 & 197404.8867 & 102857.712 & 73268.73783 & 74615.57093 & $\begin{array}{l}3 \quad 79704.80999 \\
\end{array}$ & 200115.4988 \\
\hline 157207.9659 & $9 \quad 198829.0786$ & 5 113470.0802 & $2 \quad 198120.6529$ & 64443.04139 & 197404.8861 & 102857.7213 & 73268.74035 & 74615.57223 & 79704.8089 & 200115.499 \\
\hline 157207.9633 & $\begin{array}{ll}3 & 198829.0794\end{array}$ & 113470.0846 & $\begin{array}{ll}6 & 198120.6549\end{array}$ & 64443.03948 & 197404.8846 & 102857.7158 & 73268.74086 & 74615.56928 & $\begin{array}{l}8 \quad 79704.80824\end{array}$ & 200115.4966 \\
\hline 157207.963 & $\begin{array}{ll}3 & 198829.0794\end{array}$ & 113470.0812 & $2 \quad 198120.6552$ & 64443.04123 & 197404.8885 & 102857.7155 & 73268.73729 & 74615.57207 & $7 \quad 79704.81325$ & 200115.4958 \\
\hline 157207.9623 & $\begin{array}{ll}3 & 198829.0779\end{array}$ & $\quad 113470.083$ & $3 \quad 198120.652$ & 64443.04067 & 197404.8827 & 102857.715 & 73268.73608 & 3 74615.57311 & $1 \quad 79704.80905$ & 200115.4949 \\
\hline 157207.9626 & $\begin{array}{ll}6 & 198829.0783\end{array}$ & 3 113470.082 & $2 \quad 198120.6527$ & 64443.04347 & 197404.8868 & 102857.7135 & 73268.7372 & 74615.57072 & $2 \quad 79704.80448$ & 200115.4955 \\
\hline 157207.9187 & $\begin{array}{ll}7 & 198829.0389\end{array}$ & 7 113470.0792 & 198120.62 & 64443.03917 & 197404.8609 & 102857.7138 & 73268.73359 & 74615.56798 & $\begin{array}{ll}8 & 79704.81168\end{array}$ & 200115.4672 \\
\hline 157207.8906 & $\begin{array}{ll}6 & 198829.0146\end{array}$ & $5 \quad 113470.0769$ & $9 \quad 198120.6027$ & 64443.03944 & 197404.8614 & 102857.7143 & 73268.73191 & 74615.56515 & 79704.8103 & 200115.4457 \\
\hline 157207.8884 & $\begin{array}{l}4 \quad 198829.0136\end{array}$ & 113470.0763 & $\begin{array}{l}3 \quad 198120.6028 \\
\end{array}$ & 64443.04149 & 197404.8629 & 102857.7122 & 73268.73038 & 74615.56616 & $\begin{array}{ll}6 \quad 79704.81414\end{array}$ & 200115.4428 \\
\hline 157207.8881 & $\begin{array}{ll}1 & 198829.0143\end{array}$ & $\begin{array}{l}313470.0752 \\
\end{array}$ & $2 \quad 198120.6058$ & 64443.04025 & 197404.8654 & 102857.7128 & 3) 73268.73327 & 74615.56663 & $\begin{array}{ll}3 & 79704.81329\end{array}$ & 200115.4398 \\
\hline
\end{tabular}


DEÜ FMD 22(66), 813-824, 2020

Tablo 3. CORS İstasyonları arasındaki uzaklıkların günlük değişim değerleri (m)

\begin{tabular}{|c|c|c|c|c|c|c|c|c|c|c|c|}
\hline $\begin{array}{l}\text { Jülyen } \\
\text { Günü }\end{array}$ & $\begin{array}{l}\text { MURA } \\
\text { _HAKK }\end{array}$ & $\begin{array}{r}\text { MURA } \\
\text { _SEMD }\end{array}$ & $\begin{array}{l}\text { MURA } \\
\text { SIRN }\end{array}$ & $\begin{array}{c}\text { MURA } \\
\text { SIRT }\end{array}$ & $\begin{array}{l}\text { MURA } \\
\text { MUUU } \\
\text { S L }\end{array}$ & $\begin{array}{l}\text { HAKK_ } \\
\text { SIRN }\end{array}$ & $\begin{array}{l}\text { SIRN_}_{-} \\
\text {SIRT }\end{array}$ & $\begin{array}{l}\text { SIRT }_{-} \\
\text {TVAN }\end{array}$ & $\begin{array}{l}\text { MUUS } \\
\text { SIRT } \\
\text { L }\end{array}$ & $\begin{array}{l}\text { MUUS } \\
\text { _TVAN }\end{array}$ & $\begin{array}{l}\text { HAKK } \\
\text { SEMD }\end{array}$ \\
\hline 282 & -0.00026 & 0.00337 & -0.001 & -0.00226 & 0.00599 & -0.00666 & 0.00185 & -0.00078 & 0.00056 & 0.00177 & 0.01017 \\
\hline 283 & 0.00166 & 0.00015 & 0.00152 & 0.00483 & -0.00441 & 0.00574 & 0.00173 & -0.00003 & -0.00029 & 0.00099 & -0.00117 \\
\hline 284 & -0.00338 & -0.00124 & -0.00195 & -0.00343 & -0.00512 & 0.00156 & 0.00077 & 0.00103 & -0.00227 & -0.0063 & -0.00149 \\
\hline 285 & 0.00224 & -0.00213 & -0.00093 & 0.00078 & 0.00685 & -0.00638 & -0.00456 & 0.00008 & -0.00733 & 0.00349 & 0.00232 \\
\hline 286 & 0.00248 & 0.00722 & 0.00254 & 0.00348 & 0.00576 & 0.00618 & 0.00621 & -0.00629 & 0.00203 & -0.00059 & -0.00647 \\
\hline 287 & -0.00256 & -0.00491 & -0.00228 & -0.00301 & -0.01219 & -0.00763 & -0.00074 & 0.00505 & 0.00765 & 0.00344 & 0.00655 \\
\hline 288 & -0.0001 & -0.00189 & 0.00208 & 0.00205 & 0.00261 & 0.00231 & 0.00064 & 0.00115 & -0.00176 & -0.00423 & -0.0082 \\
\hline 289 & 0.00055 & 0.00586 & 0.0032 & 0.00564 & -0.0022 & 0.00247 & -0.00141 & -0.00017 & 0.00477 & -0.00019 & 0.01043 \\
\hline 290 & -0.00058 & -0.00208 & -0.00291 & -0.00864 & 0.00421 & 0.00074 & 0.00115 & -0.00023 & -0.00839 & 0.0015 & -0.00506 \\
\hline 291 & 0.00386 & 0.0002 & -0.00105 & 0.00132 & -0.00056 & -0.00056 & -0.00135 & -0.00135 & 0.0093 & 0.0013 & -0.00109 \\
\hline 292 & -0.00267 & -0.00238 & 0.00089 & 0.00191 & -0.00155 & -0.00155 & -0.00191 & -0.00191 & -0.00548 & -0.00295 & -0.00066 \\
\hline 293 & -0.00022 & -0.00078 & $-9 \mathrm{E}-05$ & 0.00039 & 0.00395 & 0.00395 & 0.00175 & 0.00175 & -0.00026 & 0.00279 & 0.00501 \\
\hline 294 & -0.00072 & -0.00089 & -0.00143 & -0.00324 & -0.00587 & -0.00587 & -0.00056 & -0.00056 & -0.00058 & 0.00104 & -0.0042 \\
\hline 295 & 0.00024 & 0.00056 & 0.00036 & 0.00067 & 0.00411 & 0.00411 & 0.0028 & 0.00280 & -0.00147 & -0.00239 & -0.00457 \\
\hline 296 & -0.04382 & -0.02824 & -0.03938 & -0.03265 & -0.02591 & -0.02591 & -0.0043 & -0.00430 & 0.00029 & -0.00274 & 0.0072 \\
\hline 297 & -0.02811 & -0.02154 & -0.0243 & -0.01737 & 0.00055 & 0.00055 & 0.00027 & 0.00027 & 0.00047 & -0.00283 & -0.00138 \\
\hline 298 & -0.00221 & -0.00288 & -0.00096 & 0.00018 & 0.0015 & 0.0015 & 0.00205 & 0.00205 & -0.00203 & 0.00101 & 0.00384 \\
\hline 299 & -0.00035 & -0.00304 & 0.00065 & 0.00298 & 0.00245 & 0.00245 & -0.00124 & -0.00124 & 0.00062 & 0.00047 & -0.00085 \\
\hline
\end{tabular}

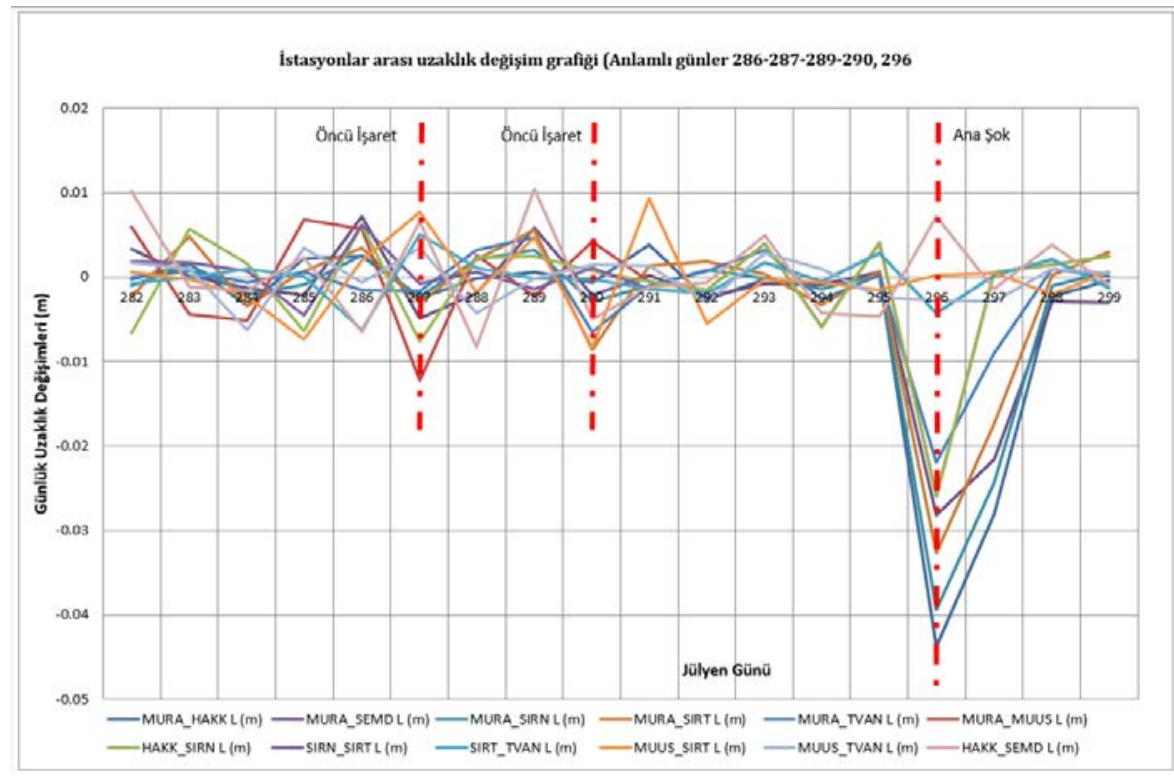

Şekil 7. TUSAGA-Aktif istasyonları arasındaki uzaklık değişim grafiği. Deprem öncesi iki öncü işaret 286-287 ve 289-290 günlerinde görünmektedir. Deprem günü (296) 4.5 cm'ye varan sıkışma da grafikte ortaya konulmuștur. 
Yukarıda anlatıldığı üzere başlangıç değerlerine göre hesaplanan istasyon koordinatlarındaki değișimler ve buna bağlı değişen istasyonlar arası uzaklıklar, tanımlanan üçgen alanlarının değerlerine değişim olarak yansımıștır. $\mathrm{Bu}$ adımda ise (1) bağıntısı kullanılarak önceki güne göre üçgen alanlarındaki değişim oranları hesaplanarak Tablo 4'te listelenmiștir. Sonuçta jülyen günleriyle ilişkili olan üçgen alanları değişim oran grafiği, deprem gününü de içerecek şekilde Şekil 8'de gösterilmektedir.
Grafik gözden geçirildiğinde büyük depremin anlamlı öncü sinyalleri dikkat çekmektedir ve grafiklerden deprem öncesi yerin ne kadar depresif olabileceği böylelikle, tıpkı giriş bölümünde bahsedilen diğer bazı yöntemlerde olduğu gibi, bir kez daha vurgu yapılmaktadır. Bu grafiklerden çıkarılacak bir başka sonuç ise, değişimlerin olduğu üçgen kenar çizgileri ve üçgen alanlarından hareketle büyük depremin hangi bölgede olabileceğinin yaklaşık olarak tespit edilebileceğidir.

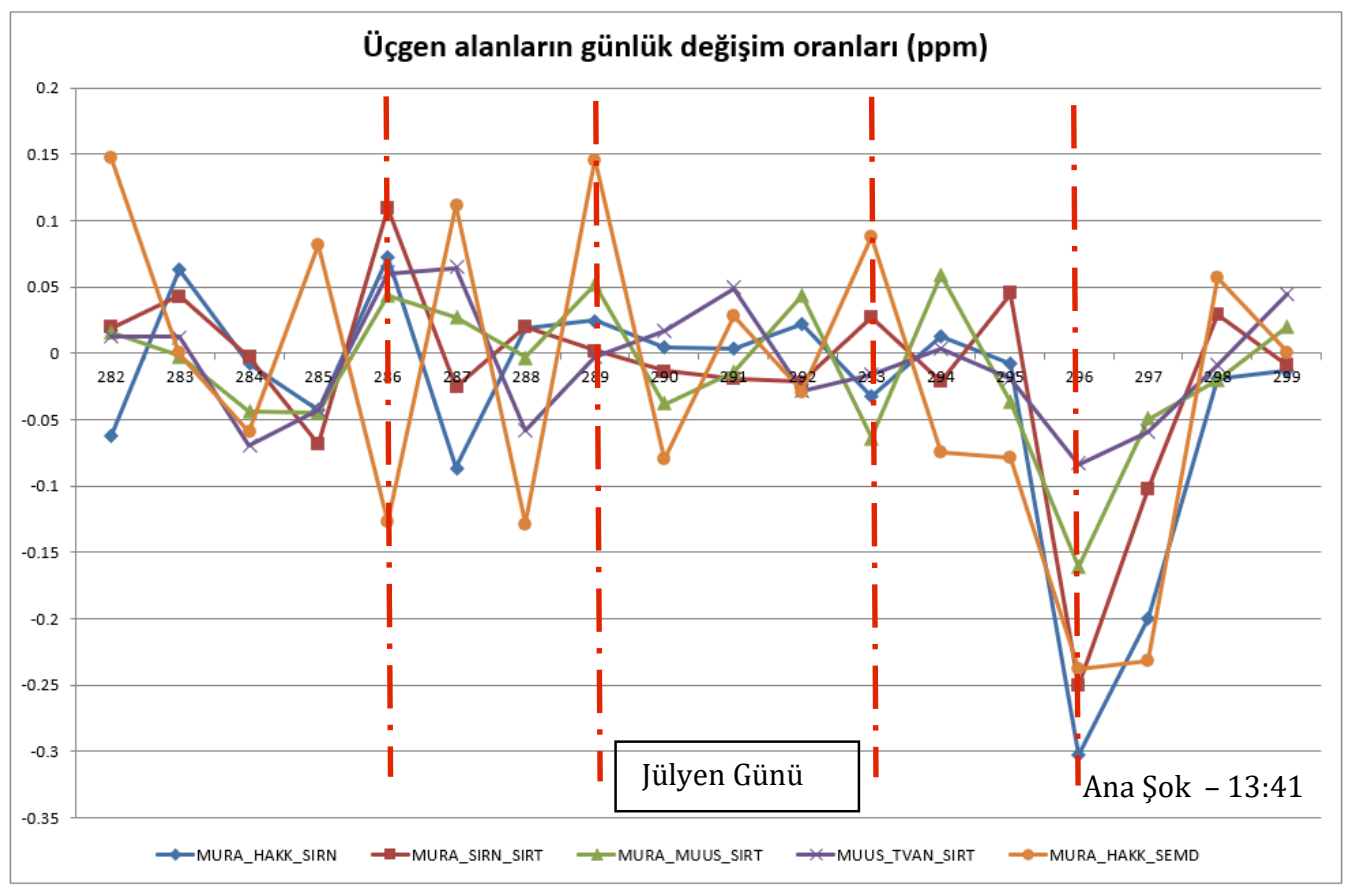

Şekil 8. Üçgen alanlarının günlük değişim oranları grafiği

Burada özellikle MURA istasyonu ile ilișkili MURA-HAKK-SEMD, MURA-HAKK-SIRN, MURASIRT-SIRN (Şekil 6) gibi üçgen alanlarının 286287, 289-290 ve 293 günlerinde ve elbette büyük depremin olduğu 296 gününde, Şekil 6'da hız vektörlerinden de görüleceği üzere, nasıl beklenmeyen anomalilerin meydana geldiğine dikkat edilmelidir. Bu iki üçgene (MURA-HAKKSEMD, MURA-HAKK-SIRN) ve oluşan faya bakıldığında (Şekil 3) fay tam da bu iki üçgenin sınırında meydana gelmiștir. SIRN ve SIRT istasyonlarını hız vektörleri her ne kadar güneybatı yönünde olsa da MURA istasyonun deplasmanı daha fazladır ve HAKK ve BASK istasyonları da bu sıkışmayı fazlalaștıracak şekilde kuzey-batı yönünde yer değiştirmişlerdir.

Bunlar yöntemin deprem tahmininde ne kadar tutarlı olabileceğini özellikle ortaya koyan sonuçlardır. 
DEÜ FMD 22(66), 813-824, 2020

Tablo 4. Üçgen alanlarının günlük değișim oranları

GÜNLÜK DEĞișiMiM ORANLARI - DCR (ppm)

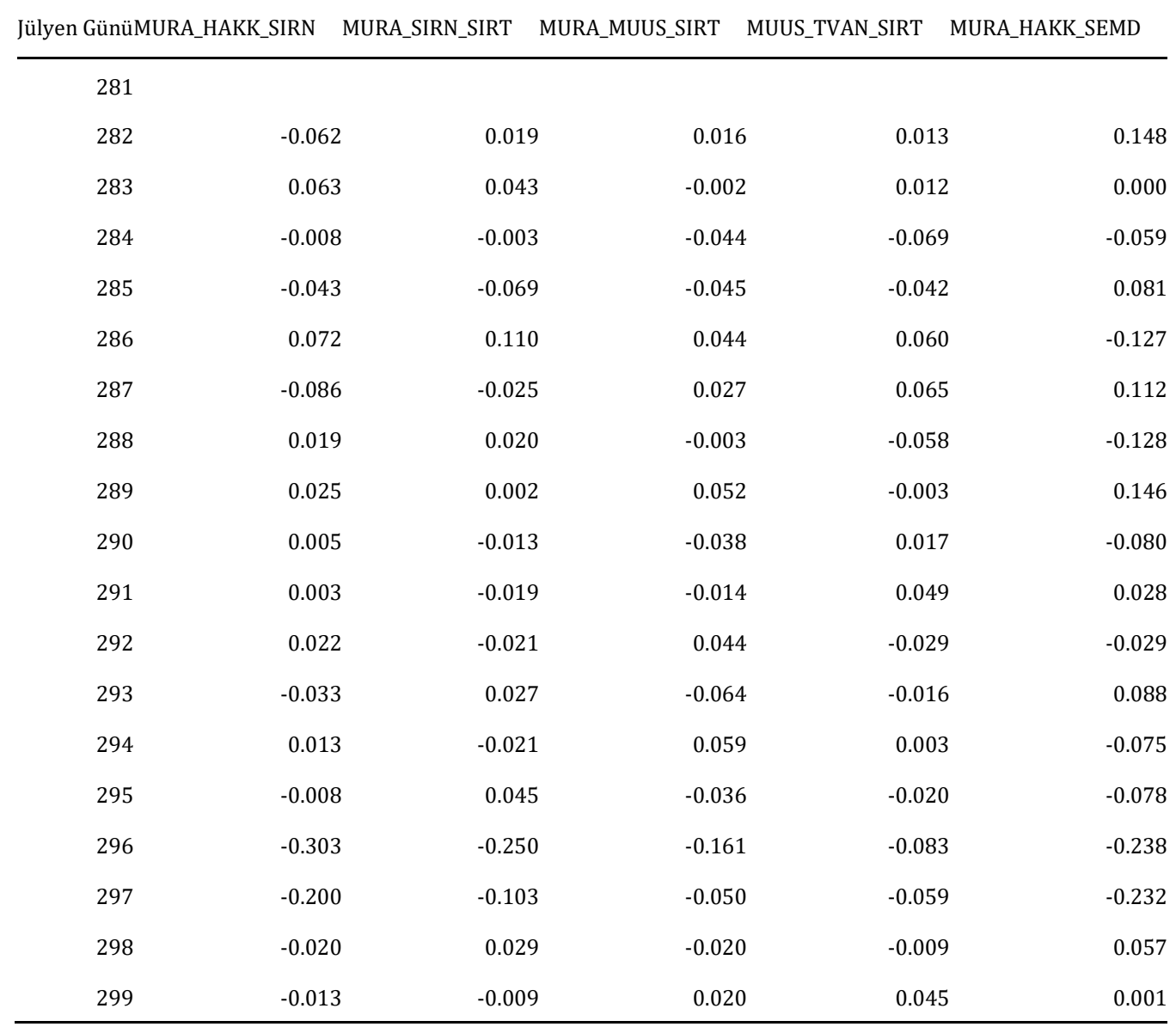

\section{Sonuçlar}

$\mathrm{Bu}$ çalışmada, CORS istasyonlarının köşe noktalarını oluşturduğu üçgen alanlarındaki değişim oranları kullanılarak 23 Ekim 2011'de meydana gelen 7.2 M aletsel büyüklüğe sahip Van depreminin bazı öncü işaretleri elde edilmeye çalışılmıştır. Elde edilen özel ve genel sonuçlar aşağıdaki gibi sıralanabilir;

Özel sonuçlar:

CORS istasyonlarından alınan veriden elde edilen günlük üçgen alan değişim oranlarının sismik veriyle uyuştuğu görülmüştür. Özellikle depremden 10 gün önce 186-187 de öncü işaretin alındığı sonrasında 189-190 ve 193 günlerinde anlamlı sonuçlar elde edilmiştir.
İstasyonların hareket vektörlerinden hareketle istasyonlar arası uzaklıklar ve üçgen alanlarındaki günlük değişimlerin hesabıyla, gerilmenin veya başka deyişle stresin nerede olduğu görülmekte ve olası depremin nerede meydana gelebileceği anlaşılabilmektedir.

Stres bölgesinin hesaplanabildiği gibi deprem öncesi oluşan mikro depremlerle de birleştirilerek olası faylanma bölgesinin tespit edilebildiği ve bunun deprem sonrası yapılan saha incelemesiyle örtüștüğü görülmüștür. Burada özellikle MURA-HAKK-SEMD, MURAHAKK-SIRN, MURA-SIRT-SIRN gibi üçgen alanlarının 286-287, 289-290 ve 293 günlerinde öncü işaretleri verdiği ve büyük depremin olduğu 296 gününde anlamlı ve gerçekçi değerler elde edilmiş ve grafikleştirilmiştir. 
Üçgen alanlarından ikisine (MURA-HAKK-SEMD, MURA-HAKK-SIRN) ve olușan faya bakıldığında fay tam da bu iki üçgenin sınırında meydana gelmiștir. SIRN ve SIRT istasyonlarını hız vektörleri her ne kadar güney-batı yönünde olsa da MURA istasyonun deplasmanı daha fazladır ve HAKK ve BASK istasyonları da bu sıkıșmayı fazlalaștıracak şekilde kuzey-batı yönünde yer değiştirmişlerdir. Böylece sıkışma ve dolayısıyla ters faylanmanın bu iki üçgen sınırında VanErçek gölleri arasında olduğu ve bu bulgunun saha gözlemleriyle de uyuştuğu gerçeği ortaya çıkmaktadır.

Genel Sonuçlar:

Büyük depremler öncesinde meydana gelen mikro depremlerin deprem tahminindeki önemi,

Bölgede yer alan CORS istasyonları ile sismik verinin nasıl anlamlı bir șekilde örtüștüğü,

CORS istasyonları ile olușturulan üçgenlerin kenar çizgilerinin ve dolayısıyla bu üçgenlerin alanlarının günlük değişim oranlarının deprem tahmininde çok anlaml sonuçlar verdiği, hatta depremin olacağı yaklaşık bölgeyi bu hareketlerden tahmin edebilme olasılığının bulunduğu,

CORS istasyon verilerinin sürekli olarak işlenmesi ve araştırmada yapılan hesaplamaların 3 boyutta sürekli olarak yapılabildiği ve gerekli merkezleri otomatik olarak uyaracak yazılımın geliștirilmesi ihtiyacının olduğu sonuçları anlamlıdır.

Burada mevcut CORS ağı ile ilgili bir iyileştirme anlamında, bu ağın özellikle fay hatları civarında, fayın her iki tarafında

Makalenin özet bölümünde değinildiği gibi pek çok yol ile deprem tahmin çalışmaları yapılmaktadır. Deprem öncesinde elde edilebilen bu bölgesel çıktıları iyi değerlendirmek ve deprem tahmininde araştırılan diğer parametreler arasındaki entegrasyonu sağlamak tahmin sonuçlarının daha güçlü, isabetli ve anlamlı olmasını sağlayacaktır.

Son olarak; CORS sistemi geliştirilmeye uygun, esnek bir sistemdir. Kurulduğu dönemde 147 olan istasyon sayısı, bugün 10 adet eklemeyle 157'ye çıkmıștır. Fay bölgeleri için yapılacak yeni projelerle, fayın her iki yakasında mühendislik veya sismolojik anakayası üzerine belirli bir sıklıkla yeni sabit istasyonlar kurulabilir ve CORS ile entegre edilebilir. $\mathrm{Bu}$ istasyonlardan elde edilecek deplasman verilerinin, yapılacak disiplinlerarası bir çalışmayla diğer tahmin parametreleriyle entegrasyonunu sağlayabilecek yeni yazılımların geliştirilmesi yoluyla anlamlı ve tutarlı deprem tahmin değerleri elde edilebilir.

\section{Teşekkür}

Yazar, yöntemin geliștiricisi ve ilk uygulayıcısı Profesör Shunji Murai tarafından 2007'de İstanbul'da verilen seminer ve paylașımları için Profesör Murai'ye özellikle teşekkürlerini sunar. Ek olarak, Tapu Kadastro Genel Müdürlüğüne ve Kandilli Rasathanesi ve Deprem Araștırma Enstitüsü'ne, Afet ve Acil Durum Yönetim Başkanlığı (AFAD), Massacushet Institute of Technology (MIT)'ye sırasıyla sağladıkları GPS, Van bölgesi sismik verisi ve akademik GAMIT/GLOBK programından dolayı teşekkür eder.

\section{Kaynakça}

[1] Emre, Ö., Duman, T.Y., Özalp, S., Elmacl, H. 2011. 23 Ekim 2011 Van Depremi Saha Gözlemleri Ve Kaynak Faya İlişkin Ön Değerlendirmeler, Jeoloji Etütleri Dairesi Yer Dinamikleri Araştırma Ve Değerlendirme Koordinatörlüğü Aktif Tektonik Araştırmaları Birimi, Maden Tetkik Ve Arama Genel Müdürlügü, Ankara.

[2] MURAI, S., ARAKI, H. 2003. Earthquake Prediction Using GPS-A New Method Based on GPS Network Triangles, GIM Volume 17, October 2003.

[3] Ürüşan, A.Y. 2015. Relations between the GNSS, InSAR, and the other techniques for prediction of earthquakes.Arab J Geosci 8, 7631-7642 https://doi.org/10.1007/s12517014-1670-x

[4] GAMIT/GLOBK Programı download and documentation (Son Erișim: 06/01/2020) http://geoweb.mit.edu/gg/docs.php

[5] Earthquake Prediction: New Findings, Challenges in a difficult Science, [Erişim Tarihi: 29.05.2009] https://www.giminternational.com/content/article/earthquake -prediction-new-findings ,

[6] Tiryakioğlu, İ., Yavașoğlu, H., Uğur, M. A., Özkaymak, C., Yılmaz, M., Kocaoğlu, H., Turgut, B. 2017. Analysis of October 23 (Mw 7.2) and November 9 (Mw 5.6), 2011 Van Earthquakes Using Long-Term GNSS Time Series, Earth Science Research Journal, Cilt 21, No.3, September 2017, s. 147-156. DOI: https://doi.org/10.15446/esrj.v21n3.62812 